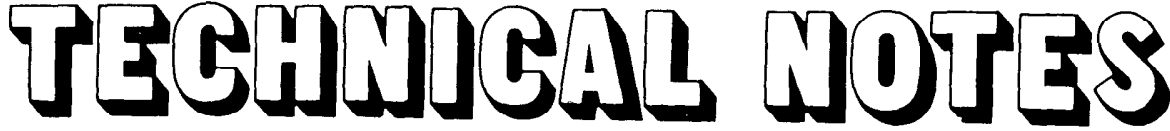

\section{A Low-Cost Machine for Separation of Roots from Soil Material}

\section{GARY R. BROWN AND JOHN F. THILENIUS}

Highlight: An efficient machine which uses water spray and agitation to separate the roots contained in soil samples from the soil material was constructed from readily available, commercial components for less than $\$ 400$.

Efficient separation of roots from soil in large quantities has been an obstacle in the study of the production of below-ground biomass. Commonly, samples have either been washed in streams, sprayed with water from a hose and the organic material caught in a sieve, or agitated in water so the organic material could be floated off. All of these methods work, but are very inefficient when many samples must be processed.

At its Pawnee Laboratory, the Grassland Biome, International Biological Program (IBP), developed a washing machine combining both water spray and agitation to separate below-ground biomass from soil. This machine was designed to work with small samples (approx. $22.5 \mathrm{~cm}^{3}$ ). During a study of the production of standing crop in alpine tundra ecosystems, we had to separate roots from soil in several thousand samples ranging up to $1,325 \mathrm{~cm}^{3}$ volume. To do this, we modified the IBP washer design, and developed an efficient, rather inexpensive, washing machine constructed from readily available materials. Up to 100 samples can be processed in a normal 8-hour working day by a single operator.

There are six major components and systems in the washer (Fig. 1):

1. The washing compartment is constructed from two roundbottom, stainless steel dairy sinks- one for the lid (1) and one for the water-holding tank (2). The sinks are hinged at the back by a piano hinge, and held together at the front with two vice-grip pliers when the

The authors are, respectively, range research technician and range scientist, Rocky Mountain Forest and Range Experiment Station, Forest Service, U.S. Department of Agriculture. Research reported here was conducted at the Station's Research Work Unit at Laramie, in cooperation with the University of Wyoming. Station's central headquarters is maintained at Fort Collins, in cooperation with Colorado State University.

Manuscript received April 21, 1976. machine is in operation. Our sinks are $35.6 \mathrm{~cm}$ deep $\times 71.2 \mathrm{~cm}$ long $(14 \times 24$ inches), but larger sizes are available. They were purchased from a major mail order company and came complete with stands and plumbing hardware.

2. The agitator (3) is a $45.7 \mathrm{~cm}$ (18-inch) diameter cylinder which rotates on a $1.9 \mathrm{~cm}(3 / 4$ inch) rod. The center rod is fitted with adjustable hubs and connected to the motor clutch system by a standard vee belt. Longitudinal brass rods $1.27 \mathrm{~cm}(1 / 2$ inch) in diameter form the body of the agitator. The rods are threaded on both ends and held in the agitator by large nuts. Alternate rods are removable and are arranged to hold 20 sample containers (see below). The agitator is supported on two pillow block bearings. Rotation of the cylinder through the water-holding tank provides the agitating action which separates the inorganic material from the organic material.

3. The sample containers $(4)$ are $7.6 \times 30 \mathrm{~cm}(3 \times 12$ inches $)$ cylinders of 40-mesh (0.4-mm openings) stainless steel screen. The screen is held in a cylindrical shape by spot welding the long axis. The ends of the cylinders are reinforced by dipping them into molten solder to a depth of about $1.2 \mathrm{~cm}(1 / 2$ inch). Plastic caps are used to close the ends of the sample containers.

4. The water supply system consists of four bathroom-type shower heads (5) located at the top of the lid. These are attached to a $1.9 \mathrm{~cm}(3 / 4$ inch) supply pipe (6) equipped with a water control valve. The strong spray action of the water from the shower heads aids in breaking up the soil particles as well as supplying water to the holding tank.

5. The overflow system has four components. A $0.95 \times 61-\mathrm{cm}(3 / 8$ $\times 24$ inches) horizontal slot (7) is located about $5 \mathrm{~cm}$ ( 2 inches) below the upper front edge of the holding tank. A stainless steel trough 8.9 $\times 12.7 \times 63.5 \mathrm{~cm}(3.5 \times 5 \times 25$ inches $)(8)$, made from 18 -gage material, is attached to the holding tank to catch the water flowing out of the slot. This trough drains into a standard 60 -mesh $(0.25 \mathrm{~mm}$ opening) soil sieve (9), which in turn drains through a gravity- 


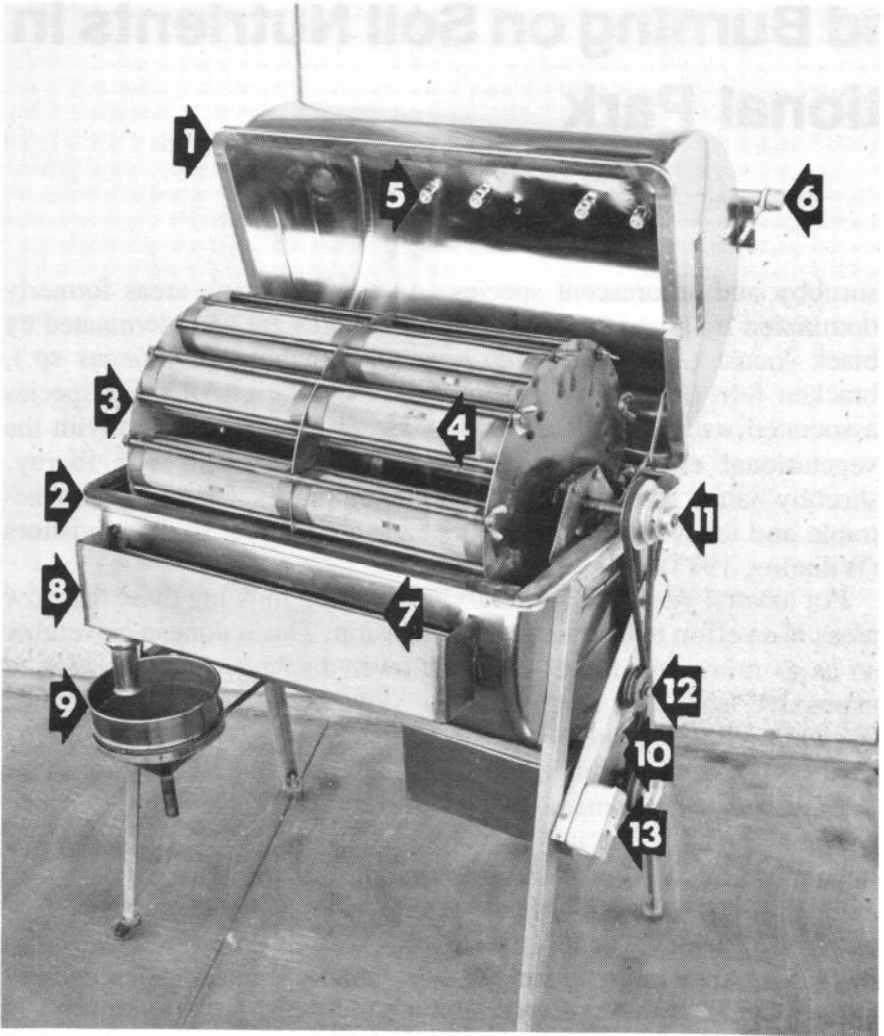

Fig. 1. Washing machine for separation of roots from soil material. Numbered arrows refer to components described in text.

feed pipe system into a 1,900-liter (500 gal) capacity settling tank (not illustrated) made from a circular, galvanized iron, stock water tank. The overflow system has two purposes: first, to keep a constant water level in the holding tank; second, to remove and catch organic particles which pass through the 40-mesh screen of the sample containers. These particles are floated on the surface of the water and are removed from the holding tank with the water flowing through the horizontal slot. The wave action generated by the rotation of the agitator drum through the water in the holding tank greatly assists in removing the small organic particles. The particles from each run are collected in the 60-mesh sieve and later used to correct the weights of the organic material remaining in the sample containers. Very few organic particles pass through the 60 -mesh sieve, but clay-sized inorganic material does pass this sieve and is collected in the settling tank to avoid excessive pollution of local sewage systems. Excess water from the settling tank flows over the edge of the tank and is allowed to sink into the ground.

6. The motor-clutch system consists of a 30 RPM geared electric motor (10), a 1:4 ratio reduction pulley system (11), and a hinged arm with an idler pulley (12) which acts as a clutch. The idler pulley is held against the drive belt by the weight of the arm. Lifting the arm removes tension from the vee belt, and the agitator drum quickly stops rotating. The control switch for the motor (13) is mounted on the end of the clutch arm both to provide additional weight to the clutch system, which helps to eliminate slippage of the drive belt, and to make the switch easily accessible.

\section{Sample Handling Procedures and Machine Operation}

Samples are broken into small pieces (maximum $5 \mathrm{~cm}$ diameter) by hand and placed in the sample containers, which are capped on both ends. Alternate brass rods are removed from the agitator drum and the sample containers loaded. The brass rods are replaced and tightly secured. The lid is closed, the water turned on, and the holding tank allowed to fill. The clutch handle is raised and the electric motor turned on. The clutch handle is then slowly lowered to tighten the drive belt and start the rotation of the agitator drum. Normally, the machine is operated for approximately 20 minutes. During operation care must be taken to see that the 60-mesh sieve does not clog with organic material and overflow.

After washing is completed, the sample containers are removed from the agitator drum and the organic material washed into a large plastic container. Excess water is decanted and any rocks or other inorganic material removed by hand. The organic material is then placed in a tared $250 \mathrm{ml}$ Pyrex beaker, dried in a forced draft oven at $105^{\circ} \mathrm{C}$ for 24 hours, and weighed to the nearest $0.1 \mathrm{~g}$. The weighed samples are ashed in a muffle furnace at $600^{\circ} \mathrm{C}$ until all organic material is consumed. The samples are then removed from the muffle furnace, allowed to cool, and reweighed to obtain a correction for any inorganic material not removed in the washing process.

The material from the 60-mesh sieve is handled similarly, except an average value is determined. This average is added to the weights of the individual samples to correct for $0.25 \mathrm{~mm}$ organic particles.

\section{List of Materials and Suppliers ${ }^{1}$}

By using as many commercially available parts as possible, construction costs were kept to a minimum. The costs listed below are 1972 prices. About 10 man-days were required for construction.

Metal Goods, Inc.

4343 Holly Street

Denver, Colorado 80216

Mesh, stainless steel fabric, $40 \times 40$ mesh, 0.010 wire, $36^{\prime \prime} \times 84^{\prime \prime}$ $\$ 66.78$

\section{Montgomery Ward}

\section{South Second}

\section{Laramie, Wyoming 82070}

2 each, tank, single, stainless steel, catalog number X89 FX20372F (with legs). \$42.00 each.

$\$ 84.00$

2 Pulleys, 4-step die-cast, cone size 03, catalog number 284C 2895.

$\$ 1.85$ each

$\$ 3.70$

2 Pillow block, ball-bearings, Size 03, catalog number 284C2817T. $\$ 5.69$ each.

$\$ 11.30$

\section{T. L. Kern Electric}

808 Custer Street

Laramie, Wyoming 82070

Dayton Gear Motor No. 5K939, electric geared 58-to-1, 30 RPM. $\$ 56.26$

Caplugs Division, Protective Closures Co.

2150 Elmwood Ave.

Buffalo, N.Y. 14207

40 Caplugs No. 3 S.C. $\$ 0.03$

$\$ 1.20$

Miscellaneous materials (brass rod, stainless steel sheet metal, plumbing fittings, electrical fittings, etc.).

$\$ 137.88$

Total cost was $\$ 360.00$.

'Mention of specific manufacturers or supplies does not constitute endorsement by the U.S. Department of Agriculture, Forest Service. 